\title{
Transumbilical versus lateral transabdominal removal of benign adnexal masses in laparoscopic surgery-A randomized trial
}

\section{Kilpio, Olga}

\author{
2017-11
}

Kilpio , O , Härkki , P S M , Mentula , M J , Jokela , R M \& Pakarinen , P I 2017 , ' Transumbilical versus lateral transabdominal removal of benign adnexal masses in laparoscopic surgery-A randomized trial ' , European Journal of Obstetrics, and Gynecology ,and Reproductive Biology , vol. 218 , pp. 49-54 . https://doi.org/10.1016/j.ejogrb.2017.08.040

http://hdl.handle.net/10138/298123

https://doi.org/10.1016/j.ejogrb.2017.08.040

publishedVersion

Downloaded from Helda, University of Helsinki institutional repository.

This is an electronic reprint of the original article.

This reprint may differ from the original in pagination and typographic detail.

Please cite the original version. 
Full length article

\title{
Transumbilical versus lateral transabdominal removal of benign adnexal masses in laparoscopic surgery-A randomized trial
}

\author{
Olga Kilpiö, Päivi S.M. Härkki, Maarit J. Mentula, Ritva M. Jokela, Päivi I. Pakarinen* \\ Department of Obstetrics and Gynecology, University of Helsinki and Helsinki University Hospital, Helsinki, Finland
}

\section{A R T I C L E I N F O}

\section{Article history:}

Received 13 February 2017

Received in revised form 24 August 2017

Accepted 30 August 2017

\section{Keywords:}

Adnexal mass

Laparoscopy

Postoperative pain

Ports

Removal route

Oxycodone

\begin{abstract}
A B S T R A C T
Objective: In laparoscopic adnexal surgery the conventional method of removing a mass from the abdominal cavity in Finland is through a $10-\mathrm{mm}$-wide lateral abdominal port. The larger the lateral trocar, the greater the risk of pain, complications and delayed recovery. Here, we assumed that adnexal mass removal through a $10-\mathrm{mm}$ umbilical port together with $5-\mathrm{mm}$ side trocars would decrease the postoperative need of analgesics when compared with removal through a $10-\mathrm{mm}$ lateral abdominal port. Study design: Women scheduled for laparoscopic surgery of a benign adnexal mass were invited to participate. The participants were randomized into two groups: removal via the transumbilical (TU) $(n=21)$ or lateral transabdominal $(T A)(n=21)$ route. General anesthesia and use of local anesthetics were standardized. The amount of postoperative opioid (oxycodone) and visual analog scale (VAS) scores for pain were the primary outcome measures. Secondary outcome measures were nausea/vomiting (VAS evaluation), time to discharge, peri- and postoperative complications, surgeons' opinions of the alternative methods and patients' satisfaction, evaluated via a questionnaire sent six months postoperatively.

Results: There were no significant differences in the use of opioids or median pain-VAS scores between the groups during the first $24 \mathrm{~h}$ postoperatively. However, in the TU group the amount of women with very low pain-VAS scores (0-1) during the whole 12-h follow-up time was significantly greater than in the TA group ( 4 vs. 0 women $p=0.04$ ). The amounts of nausea and vomiting, and median times to discharge were similar in both groups. There were no major complications.

Conclusions: Both transumbilical and transabdominal routes of abdominal mass removal during laparoscopy were feasible and safe. However, the transumbilical route resulted in more women with very low pain-VAS scores.
\end{abstract}

(C) 2017 Elsevier B.V. All rights reserved.

\section{Introduction}

Minimally invasive laparoscopy is the approach of choice in gynecologic surgery today. It brings many benefits, such as decreased pain and enhanced recovery [1-3]. However, there is always a need to improve practices. Usually, during laparoscopic adnexal mass surgery the trocar needed for mass removal should be at least $10 \mathrm{~mm}$ wide. The incision often has to be enlarged to enable the retrieval of any larger mass. The recommendation is to suture the fascia of any incision of $\geq 10 \mathrm{~mm}$, to avoid herniation [4-8]. The risk is low $(0.18-0.6 / 1000)[4,5,9]$, but trocar hernias at

\footnotetext{
* Corresponding author at: Women's Hospital, Department of Obstetrics and Gynecology, University of Helsinki and Helsinki University Hospital, Haartmaninkatu 2, Helsinki, P.O. Box 140, FIN-00029 HUS, Finland.

E-mail address: paivi.pakarinen@hus.fi (P.I. Pakarinen).
}

extra-umbilical locations represent most $(75 \%)$ cases $[7,10]$. The fascia of a 5-mm incision does not need to be closed because of the minimal risk of herniation [6]. In cases of $10-\mathrm{mm}$ incisions, sutures are usually applied using a special endosuture needle to pass the thread through the fascia edges. The pain increases, the further the sutures are placed apart. Despite local infiltration of anesthetic, wound pain may delay recovery [10,11]. Additionally, puncture of the epigastric artery, or its branch, is a concern when using larger lateral trocars $[9,12,13]$.

Adnexal mass removal from the abdominal cavity may alternatively be performed by using suprapubic [15,16], umbilical or vaginal pathways [17-20]. Unlike in urological or gastrointestinal surgery, evidence for the feasibility of transumbilical mass retrieval in gynecology is sparse. Because umbilical opening requires only a vertical incision into the fascia and rectus sheath, the risk of blood vessel lesion is minimal. Sutures can be easily placed near the edges of the fascia to avoid extra tension, even if a 
larger opening of the fascia is needed, as in single-port laparoscopic surgery $[14,21]$. In transumbilical surgery additional trocars needed may be only $5 \mathrm{~mm}$ wide.

The purpose of this study was to compare transumbilical and lateral transabdominal laparoscopic removal of benign adnexal masses. Our main hypothesis was that by removing tissue through a $10-\mathrm{mm}$ umbilical port instead of a $10-\mathrm{mm}$ lateral abdominal port we could decrease postoperative pain. The primary outcome measures were the need of postoperative opioids (oxycodone) and severity of postoperative pain. Secondary outcomes were postoperative nausea, length of hospital stay, complications, and patients' and gynecologists' opinions of the methods used.

\section{Materials and methods}

This randomized prospective trial was conducted at Kätilöopisto Maternity Hospital, Helsinki University Hospital, between November 2014 and May 2015. Altogether, 42 women scheduled for adnexal laparoscopy, such as for unilateral or bilateral ovarian cystectomy, salpingectomy, oophorectomy or salpingo-oophorectomy, agreed to participate in the study (Fig. 1-flow chart). Written informed consent was obtained from all women. Background information including age, body mass index (BMI) and operative history, was recorded at admission. Exclusion criteria were contraindications to any of the forms of medication used in the study (oxycodone, ketoprofen, paracetamol), language difficulties (inability to understand and speak Finnish or Swedish), diameter of the cyst $\geq 10 \mathrm{~cm}$ or suspected malignancy detected by vaginal sonography. The participants were randomly assigned to undergo umbilical or lateral abdominal laparoscopic removal of an adnexal mass. Randomization was carried out by means of opaque, numbered envelopes, opened by a surgeon in the operating room before the operation. Twenty-one women were randomized to the transumbilical (TU) group and 21 to the lateral transabdominal (TA) group. Follow-up in both groups was six months. The study design was approved by the local Ethics Committee of Helsinki and Uusimaa district (98/13/03/03/2014) on 27 March 2014. This study was registered at ClinicalTrials.gov (NCT02704663).

All operations were performed using a standardized anesthesiology protocol. Every patient received $1 \mathrm{~g}$ paracetamol as premedication. Standardized monitoring was used. Anesthesia was induced and maintained with controlled infusion of propofol and remifentanil. Tracheal intubation was facilitated with rocuronium. The patients were ventilated with a mixture of oxygen in air. To prevent postoperative nausea and vomiting all patients were given dexamethasone $(5 \mathrm{mg})$ at the start of anesthesia and ondansetron ( $4 \mathrm{mg})$ with droperidol $(0.1 \mathrm{mg} / 10 \mathrm{~kg})$ at the end of the operation. Every patient also received fentanyl $(1 \mathrm{mg} / \mathrm{kg})$ and ketoprofen $(100 \mathrm{mg})$ at the end of the procedure for pain control.

All the operations were performed by senior consultants with the assistance of trainees or by trainees under the guidance of senior consultants. All senior consultants were experienced surgeons who had earlier mostly used lateral transabdominal ports for retrieval of an adnexal mass. The patients were in the lithotomy position. Pneumoperitoneum was achieved in all patients via insertion of a Veress needle through the umbilicus. In the TU group a $10-\mathrm{mm}$ trocar for the $10-\mathrm{mm}, 0^{\circ}$ optical device was inserted, and three $5-\mathrm{mm}$ trocars in the left and right paramedian and suprapubic regions were placed under direct visualization. After cyst, ovary or adnexal extirpation, a "Teleflex" Rush MemoBag (Picture 1) was introduced blindly into the abdominal cavity through the umbilical port, after temporary removal of the optics. The bag was then opened and the specimen inserted. The bag was closed and the tip of the thread was pushed with the same grasper to the umbilical port and out of the abdominal cavity at the same time as the camera was pulled out.

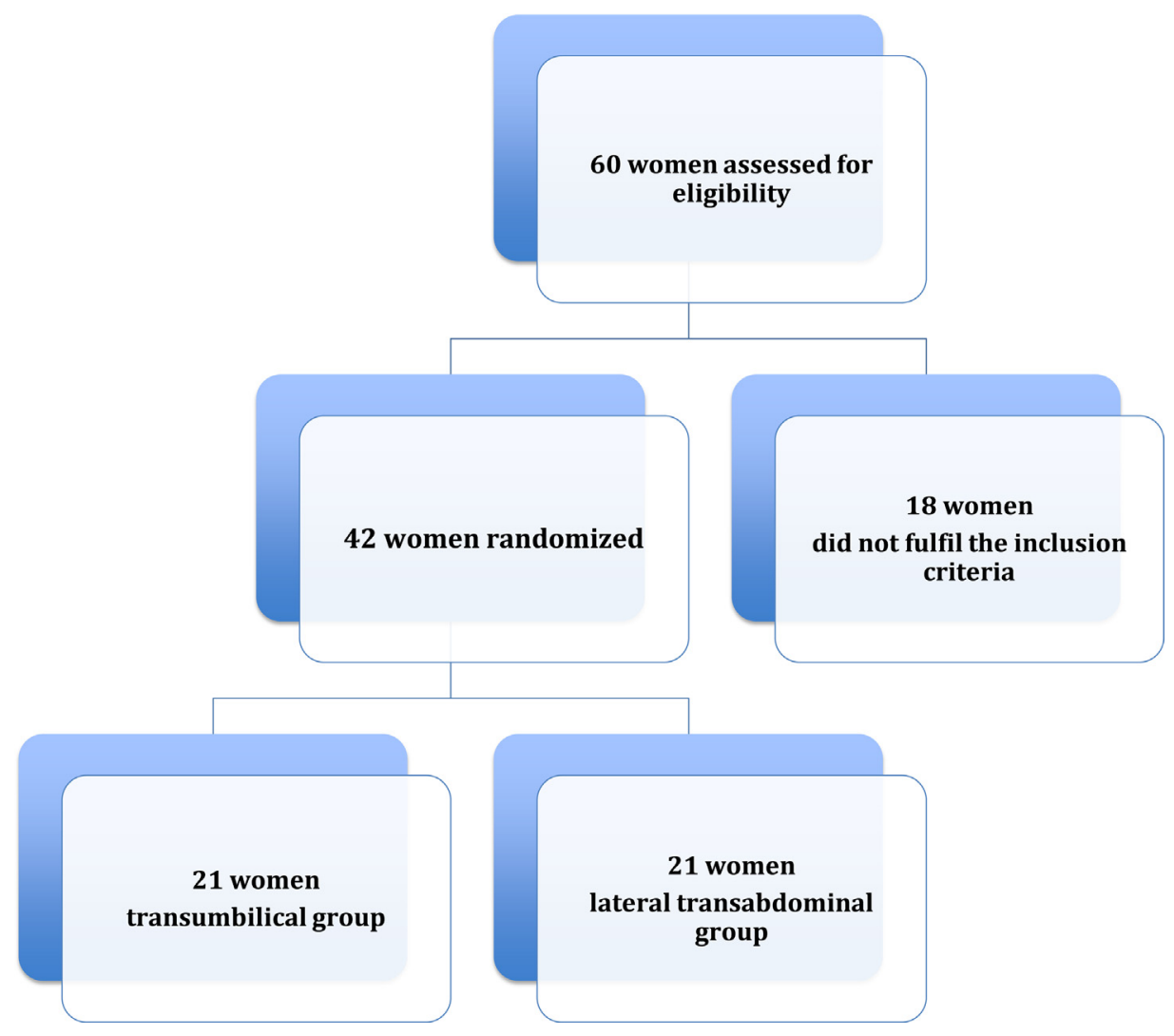

Fig. 1. Flow diagram showing the study randomization. 


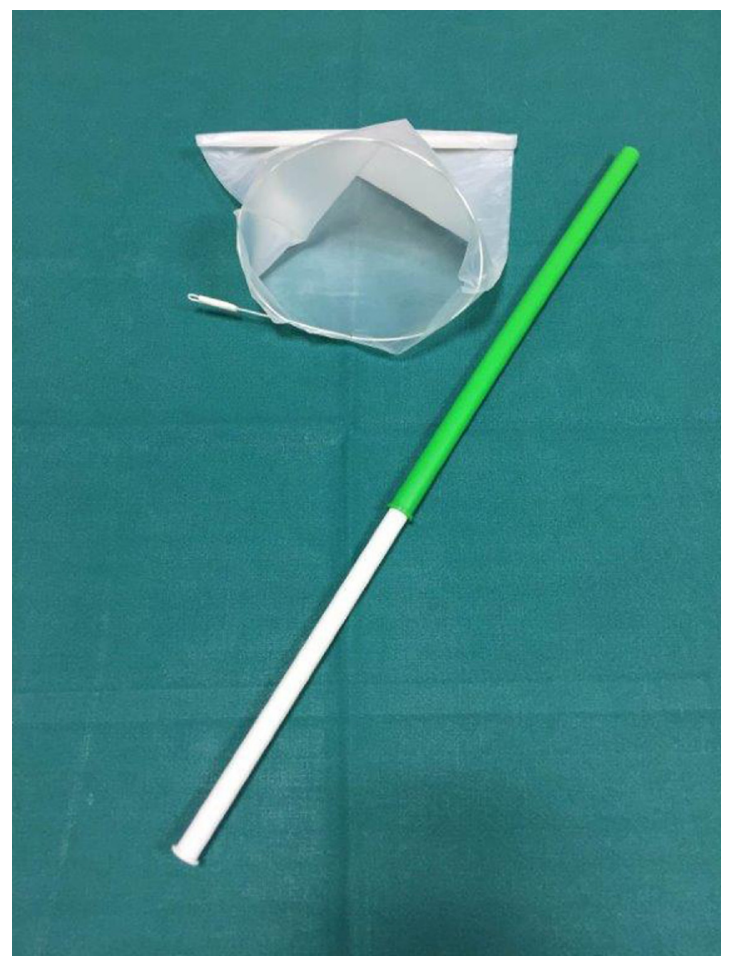

Picture 1. a "Teleflex" Rush MemoBag.

The edges of the bag were pulled out of the abdominal cavity, opened and the fluid removed by suction, after which the bag with all remaining contents was removed. The fascia at the umbilicus was closed under direct visual control with 0-Vicryl sutures using a traditional needle holder. The fascias at the $5-\mathrm{mm}$ incisions were not closed. The skin incisions were closed with absorbable sutures. At the end of the operation $20 \mathrm{ml}$ of $7.5 \%$ ropivacain was infiltrated to the trocar incisions, $5 \mathrm{ml}$ to each.

The traditional protocol for removing adnexal masses in laparoscopic gynecologic surgery in Finland has been the lateral abdominal route. In the TA group a $10-\mathrm{mm}$ umbilical trocar for the $10-\mathrm{mm}, 0^{\circ}$ optical device was inserted and another $10-\mathrm{mm}$ trocar in the left paramedian region with two 5-mm trocars in the right paramedian and suprapubic regions were placed under direct visualization. The adnexal mass was placed in an endobag with a shaft (Covidien Endo Catch specimen retrieval pouch; Picture 2) inserted through the left paramedian $10-\mathrm{mm}$ port with an introducer. The bag was removed through the same $10-\mathrm{mm}$ lateral abdominal incision. The fascia at the $10-\mathrm{mm}$ lateral port was closed with 0-Vicryl sutures using a Berci fascial closure instrument. The fascia at the umbilicus was closed under direct visual control with a 0 -Vicryl single suture using a traditional needle holder. The fascias at the 5-mm incisions were not closed. Skin incisions were closed with absorbable sutures. At the end of the operation $20 \mathrm{ml}$ of $7.5 \%$ ropivacain was infiltrated to every trocar incision, $5 \mathrm{ml}$ to each.

In the post-anesthesia care unit postoperative pain was treated with an intravenous dose of oxycodone $(3 \mathrm{mg}$ ) if the visual analog scale (VAS) score was $\geq 5$. On the surgical ward every patient received paracetamol $(1 \mathrm{~g} / 6 \mathrm{~h})$ and ibuprofen $(600 \mathrm{mg} / 6 \mathrm{~h})$ if the VAS score was $\leq 3$, and an intramuscular dose of oxycodone ( $5 \mathrm{mg}$ ) on request if the VAS score was $\geq 4$ at rest. The total amount of oxycodone was recorded from the end of surgery until discharge. In addition, at 1, 3, 6, 12 and $24 \mathrm{~h}$ after surgery, the patients used VAS scores to record the severity of their postoperative incisional pain, 0 indicating no pain and 10 indicating unbearable pain.

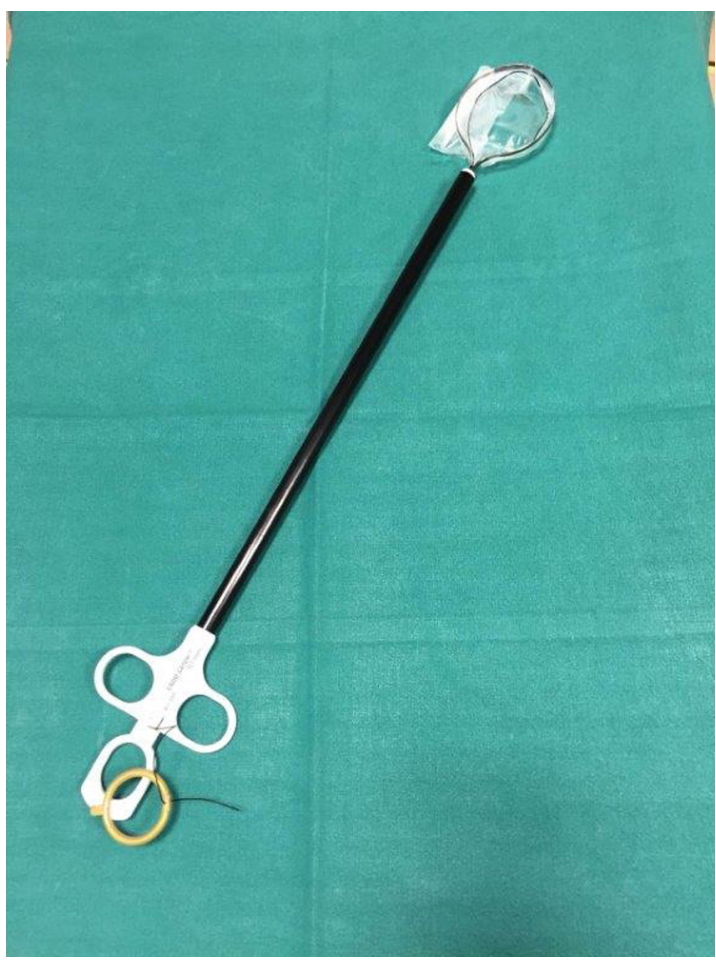

Picture 2. Endobag usea in lower transabdominal group.

VAS scores were used for estimating postoperative nausea and vomiting over the same time periods. The length of hospital stay was counted from the end of the operation until discharge. All patients were sent a questionnaire six months postoperatively in order to evaluate their recovery. Finally, the operating gynecologists were asked (by email) about their preferred surgical route.

\section{Power calculation}

Power calculation was based on a previous finding that the median need for pain medication by oxycodone is $10 \mathrm{mg}$ after laparoscopic surgery for an adnexal mass during hospital stay [21]. The use of an umbilical endobag was assumed to reduce the median oxycodone dose to $5 \mathrm{mg}$. With $80 \%$ power $(\alpha=0.05)$, using a two-sample $t$-test, 17 patients per group would be needed. A $10 \%$ dropout rate was assumed and thus 20 patients were needed in each group.

\section{Statistical analysis}

All analyses were performed with SPSS software, version 20 (IBM SPSS Inc., IL., USA). The results are presented as medians and interquartile ranges (IQRs), or $\mathrm{n}(\%)$. Differences in continuous variables were analyzed by means of the Mann-Whitney $U$-test for skewed data. Chi-square or Fisher's exact tests were used as appropriate for independent nominal data. Statistical significance was defined as $p<0.05$.

\section{Results}

There were 21 women in each group; their demographic characteristics are described in Table 1 . There were no significant differences between the groups.

The total dose of oxycodone used was similar in both groups: $6 \mathrm{mg}(2.5-10)$ vs. $5.5 \mathrm{mg}(0-10.8)$ in the TU and TA groups, 
Table 1

Demographics of women undergoing laparoscopy for benign adnexal masses.

\begin{tabular}{|c|c|c|c|}
\hline Variable & Transumbilical group $(\mathrm{n}=21)$ & Lower lateral transabdominal group $(\mathrm{n}=21)$ & p-value \\
\hline Age (years) & $42(35-56)$ & $44(29-56)$ & 0.73 \\
\hline BMI $\left(\mathrm{kg} / \mathrm{m}^{2}\right)$ & $25(22-26)$ & $25(23-29)$ & 0.36 \\
\hline Painkiller use & $2(9.5)$ & $1(5.0)$ & 0.58 \\
\hline Previous surgery & $11(52.4)$ & $9(45.0)$ & 0.63 \\
\hline ASA physical status & $1(1-2)$ & $1(1-2)$ & 1 \\
\hline 1 & $11(52.4)$ & $14(70)$ & 0.35 \\
\hline 2 & $9(4.9)$ & $6(30)$ & 0.33 \\
\hline 3 & $1(4.8)$ & - & 0.31 \\
\hline \multicolumn{4}{|l|}{ Indications } \\
\hline Endometriosis & $6(29 \%)$ & $7(32 \%)$ & 0.74 \\
\hline Dermoid cyst & $4(19 \%)$ & $3(15 \%)$ & 0.68 \\
\hline Simplex cyst & $7(32 \%)$ & $1(5 \%)$ & 0.02 \\
\hline Cystadenoma & $2(10 \%)$ & $3(14 \%)$ & 0.63 \\
\hline Breast cancer & $1(5 \%)$ & $5(24 \%)$ & 0.08 \\
\hline Sactosalpinx & $1(5 \%)$ & $1(5 \%)$ & 1 \\
\hline Fibroma & 0 & $1(5 \%)$ & 0.31 \\
\hline
\end{tabular}

Data are presented as $\mathrm{n}(\%)$ or median (interquartile range [IQR]).

Table 2

Use of oxycodone, pain (VAS scores) and time to discharge among the women undergoing laparoscopy.

\begin{tabular}{|c|c|c|c|}
\hline Variable & Transumbilical group & Transabdominal group & p-value \\
\hline \multicolumn{4}{|l|}{ Postoperative pain (VAS score) } \\
\hline $1 \mathrm{~h}$ & $1.5(0-8)$ & $2(0-8)$ & 0.82 \\
\hline $3 \mathrm{~h}$ & $1(0-4)$ & $1(0-7)$ & 0.78 \\
\hline $6 \mathrm{~h}$ & $2(0-5)$ & $3(0-8.5)$ & 0.07 \\
\hline $12 \mathrm{~h}$ & $3(0-8)$ & $3(0-8)$ & 0.18 \\
\hline $24 \mathrm{~h}$ & $3(0-7)$ & $3(0-7.5)$ & 0.75 \\
\hline Max pain & $4(1-8)$ & $4(1-8.5)$ & 0.62 \\
\hline VAS $\geq 7$ & $3(14.3 \%)$ & $5(23.8 \%)$ & 0.43 \\
\hline $\mathrm{VAS} \leq 4$ & $8(38.1 \%)$ & $8(38.1 \%)$ & 1.00 \\
\hline VAS $0-1$ during the first $12 \mathrm{~h}$ after operation & $4(19 \%)$ & $0(0 \%)$ & 0.04 \\
\hline Time to discharge (min) & $360(180-1440)$ & $345(150-1080)$ & 0.27 \\
\hline Oxycodone (mg) & $6(2.5-10)$ & $5.5(0-10.8)$ & 0.64 \\
\hline Postoperative nausea and vomiting (VAS score) & 0 & 0 & - \\
\hline Operative time (min) & $70(43-95)$ & $80(65-100)$ & 0.076 \\
\hline Bleeding $(\mathrm{ml})$ & $0(0-10)$ & $0(0-100)$ & 0.16 \\
\hline Major complication & 0 & 0 & \\
\hline
\end{tabular}

Data are presented as $\mathrm{n}(\%)$ or median (interquartile range [IQR]).

respectively (Table 2). VAS scores for pain after surgery and median maximal pain did not differ statistically between the groups. Postoperative pain scores were also analyzed to see whether there were differences in severe pain (VAS $\geq 7$ ) or low pain (VAS $<4$ ). No significant differences in these values were found. However, there was a difference between the groups when pain scores of $0-1$ during the first $12 \mathrm{~h}$ after operation were analyzed (TA 0 [0\%] vs. TU 4 [19.0\%], $p=0.04$ ). This difference was not due to increased use of oxycodone because patients with lower pain scores received less analgesic.

Table 3

Questionnaire and related responses six months after operation.

\begin{tabular}{|c|c|c|c|}
\hline & Transumbilical group $(n=21)$ & Lower lateral transabdominal group $(n=21)$ & p-value \\
\hline Response rate & $15(71 \%)$ & $20(95 \%)$ & 0.038 \\
\hline \multicolumn{4}{|c|}{ Did you have any problems in the recovery period? $\mathrm{N}$ (response rate) } \\
\hline YES & $4(27 \%)$ & $6(30 \%)$ & 0.83 \\
\hline NO & $11(63 \%)$ & $14(70 \%)$ & 0.83 \\
\hline \multicolumn{4}{|c|}{ Are you satisfied with the cosmetic outcome of your operation? N (response rate) } \\
\hline YES & $14(93 \%)$ & $19(95 \%)$ & 0.83 \\
\hline NO & $1(7 \%)$ & $1(5 \%)$ & 0.83 \\
\hline \multicolumn{4}{|c|}{ Were you given sufficient sick-leave to recover properly? $\mathrm{N}$ (response rate) } \\
\hline YES & $10(67 \%)$ & $15(75 \%)$ & 0.59 \\
\hline NO & $5(33 \%)$ & $5(25 \%)$ & 0.59 \\
\hline \multicolumn{4}{|c|}{ For how many days did you need painkillers after your operation? Days (range) } \\
\hline & $6(2-7)$ & $5(3-8)$ & 0.67 \\
\hline \multicolumn{4}{|c|}{ Would you have this operation again? $\mathrm{N}$ (response rate) } \\
\hline YES & $15(100 \%)$ & $20(100 \%)$ & N.S \\
\hline NO & $0(0 \%)$ & $0(0 \%)$ & \\
\hline \multicolumn{4}{|c|}{ Would you recommend this operation to others? $\mathrm{N}$ (response rate) } \\
\hline YES & $13(87 \%)$ & $20(100 \%)$ & 0.09 \\
\hline NO & $2(13 \%)$ & $0(0 \%)$ & \\
\hline
\end{tabular}


There were no differences between the study groups in VAS scores for nausea or vomiting, operative bleeding, operative time, major complications or postoperative satisfaction of patients.

Every gynecologic surgeon $(n=19)$ performing the procedures preferred the transumbilical route.

Most of those women who completed a questionnaire six months after surgery $(33 / 35,94 \%)$ were satisfied with the operation and they would also recommend it to others. Two patients, one in each group, were dissatisfied with the cosmetic outcome. Altogether, 10 patients (24\%) had minor problems during the recovery period, but there was no difference between the groups. In the TU group two patients experienced umbilical wound secretion, one had a postoperative infection and one had a hematoma in the area of the lateral port. In the TA group four patients had pain in the lateral trocar region and two patients had a hematoma in the lateral trocar area. During the follow-up period no postoperative trocar hernias were found. The average duration of pain medication in the TU group was six days, and in the TA group, five days. A third of the patients in the TU group wished for longer sick-leave to recover, vs. $25 \%$ in the TA group (NS; Table 3).

\section{Comments}

This randomized study was planned to improve recovery after laparoscopic surgery. Our hypothesis was that smaller incisions in the lower abdominal wall and the use of an umbilical endobag would reduce postoperative pain and need of opioids. The need of oxycodone did not differ significantly between the groups. Also, the median pain-VAS scores, scores of very intense pain (VAS $\geq 7$ ) or low pain (VAS $<4$ ) were not significantly different between the groups. However, there were more patients in the TU group having very low pain-VAS scores (VAS $0-1$ ) during the first $12 \mathrm{~h}$ after operation (TA 0 [0\%] vs. TU 4 [19.0\%], $p=0.04$ ).

There are various reasons for our findings. Firstly, use of local anesthesia in trocar incisions may have reduced pain effectively $[10,11]$ in both groups. Secondly, the use of oxycodone was lower than expected and estimated in the power calculation; thus the study may have been underpowered. However, use of the umbilical port for adnexal mass removal was associated with a tendency towards shorter operative times, made possible because of faster and easier closure of the incision. It was also associated with more women with very low pain-VAS scores during the first $12 \mathrm{~h}$ of follow-up.

Importantly, we showed that the umbilical and abdominal pathways of tissue removal were equally feasible and safe in laparoscopic adnexal surgery. The amount of pain medication, postoperative pain, and wound healing were similar in both groups and no major complications occurred. There was no significant difference in time to discharge or length of sick-leave. Patients were equally satisfied with both methods. All gynecologic surgeons performing the procedures preferred the transumbilical route and this is now the routine method in our department for laparoscopic specimen retrieval.

The strengths of our study were the randomized nature of the trial and the strict control of pain and medication. Follow-up after discharge enabled monitoring of late complications and recovery.

Recently, other investigators [22] assessed postoperative pain after laparoscopic retrieval of benign adnexal tumors, with a follow-up time of $24 \mathrm{~h}$. Use of the transabdominal route caused more immediate postoperative pain compared with the transumbilical route, but pain scores subsequently converged. They concluded that removal of benign adnexal masses via an umbilical port was associated with a shorter retrieval time and produced less pain. Their study protocol differed from ours in port sites used and inquiry about pain, and they did not report the amount of pain medication. In addition, unlike them, we infiltrated local anesthetic into port sites at the end of the operation. Despite many methodological differences, their results are convergent with ours as regards operation time, time to discharge, complication rate and blood loss.

There are several options as regards the removal of tissues in laparoscopy. The transvaginal route may be less painful than the transumbilical route [17]. The transvaginal route has been considered to be basically safe. However, it may carry a risk of injury to adjacent organs such as the bowel, ureters or vagina and may cause dyspareunia if the wound is scarred [23].

In gynecology as well as in other surgical specialities, an attempt is made to minimize the size of abdominal incisions. The benefits are decreased risks of wound infection, incisional hernias and postoperative pain, a quicker return to normal life, improved cosmetic results and greater patient satisfaction. During laparoscopic entry, trocar placement may cause abdominal wall blood vessel and nerve injuries or hernias [12]. The risk is lower if smaller trocars are used $[4,7]$. Transumbilical retrieval of specimens allows the use of 5-mm secondary ports. Even if the umbilical incision is widened during removal of the specimen, the risk of hernia seems to be lower in umbilical vs. lateral abdominal trocar wounds [7]. Finally, umbilical incisions cause less pain than other abdominal incisions in single-site surgery [20].

We conclude that in laparoscopic adnexal mass removal, both routes are feasible and safe. The umbilical route could be considered as the first option, because more women in the TU group experienced only very low-level postoperative pain and this route was the surgeons' preference.

\section{Conflict of interest}

The authors report no conflicts of interest.

\section{References}

[1] Borendal Wodlin N, Nilsson L, Carlsson P, Kjolhede P. Cost-effectiveness of general anesthesia vs spinal anesthesia in fast-track abdominal benign hysterectomy. Am J Obstet Gynecol 2011;205(October (4))326 e1,326. e7.

[2] Hilger WS, Magrina JF, Magtibay PM. Laparoscopic management of the adnexal mass. Clin Obstet Gynecol 2006;49(September (3)):535-48.

[3] Kehlet H. Fast-track surgery-an update on physiological care principles to enhance recovery. Langenbecks Arch Surg 2011;396(June (5)):585-90.

[4] Kadar N, Reich H, Liu CY, Manko GF, Gimpelson R. Incisional hernias after major laparoscopic gynecologic procedures. Am J Obstet Gynecol. 1993;168(May (5)):1493-5.

[5] Tonouchi H, Ohmori Y, Kobayashi M, Kusunoki M. Trocar site hernia. Arch Surg 2004;139(November (11)):1248-56.

[6] Yamamoto M, Minikel L, Zaritsky E. Laparoscopic 5-mm trocar site herniation and literature review. JSLS 2011;15(January-March (1)):122-6.

[7] Lajer H, Widecrantz S, Heisterberg L. Hernias in trocar ports following abdominal laparoscopy. A review. Acta Obstet Gynecol Scand 1997;76(May (5)):389-93.

[8] Rabinerson D, Avrech O, Neri A, Schoenfeld A. Incisional hernias after laparoscopy. Obstet Gynecol Surv 1997:52(November (11)):701-3.

[9] Karthik S, Augustine AJ, Shibumon MM, Pai MV. Analysis of laparoscopic port site complications: a descriptive study. J Minim Access Surg 2013;9(April (2)):59-64.

[10] Alessandri F, Lijoi D, Mistrangelo E, Nicoletti A, Ragni N. Effect of presurgical local infiltration of levobupivacaine in the surgical field on postsurgical wound pain in laparoscopic gynecological surgery. Acta Obstet Gynecol Scand 2006;85(7):844-9.

[11] Fong SY, Pavy TJ, Yeo ST, Paech MJ, Gurrin LC. Assessment of wound infiltration with bupivacaine in women undergoing day-case gynecological laparoscopy. Reg Anesth Pain Med 2001;26(March-April (2)):131-6.

[12] Jansen FW, Kapiteyn K, Trimbos-Kemper T, Hermans J, Trimbos JB. Complications of laparoscopy: a prospective multicentre observational study. Br J Obstet Gynaecol 1997;104(May (5)):595-600.

[13] Martin-Malagon A, Arteaga I, Rodriguez L, Alarco-Hernandez A. Abdominal wall hematoma after laparoscopic surgery: early treatment with selective arterial transcatheter embolization. J Laparoendosc Adv Surg Tech A 2007 Dec;17(December (6)):781-3.

[14] Lim SW, Huh JW, Kim YJ, Kim HR. Vertical transumbilical incision versus left lower transverse incision for specimen retrieval during laparoscopic colorectal surgery. Tech Coloproctol 2013;17(February (1)):59-65. 
[15] Facy O, De Magistris L, Poulain V, Goergen M, Orlando G, Azagra JS. Right colectomy: value of the totally laparoscopic approach. J Visc Surg 2013;150 (June (3)):207-12.

[16] Akdemir A, Ergenoglu AM, Akman L, Yeniel AO, Sendag F, Oztekin MK. A novel technique for laparoscopic removal of the fallopian tube after ectopic pregnancy via transabdominal or transumbilical port using homemade bag: a randomized trial. J Res Med Sci 2013;18(September (9)):777-81.

[17] Ghezzi F, Cromi A, Uccella S, Bogani G, Serati M, Bolis P. Transumbilical versus transvaginal retrieval of surgical specimens at laparoscopy: a randomized trial. Am J Obstet Gynecol 2012;207(August (2))112 e1,112. e6.

[18] Casciola L, Codacci-Pisanelli M, Ceccarelli G, Bartoli A, Di Zitti L, Patriti A. A modified umbilical incision for specimen extraction after laparoscopic abdominal surgery. Surg Endosc 2008;22(March (3)):784-6.

[19] Ghezzi F, Cromi A, Uccella S, Siesto G, Bergamini V, Bolis P. Transumbilical surgical specimen retrieval: a viable refinement of laparoscopic surgery for pelvic masses. BJOG 2008;115(September (10)):1316-20.
[20] Fagotti A, Bottoni C, Vizzielli G, Gueli Alletti S, Scambia G, Marana E, et al. Postoperative pain after conventional laparoscopy and laparoendoscopic single site surgery (LESS) for benign adnexal disease: a randomized trial. Fertil Steril 2011;96(July (1))255 259. e2.

[21] Jokela R, Ahonen J, Tallgren M, Haanpaa M, Korttila K. Premedication with pregabalin 75 or $150 \mathrm{mg}$ with ibuprofen to control pain after day-case gynaecological laparoscopic surgery. Br J Anaesth 2008;100(June (6)):834-40.

[22] Chou LY, Sheu BC, Chang DY, Huang SC, Chen SY, Hsu WC, et al. Comparison between transumbilical and transabdominal ports for the laparoscopic retrieval of benign adnexal masses: a randomized trial. Eur J Obstet Gynecol Reprod Biol 2010;153(December (2)):198-202.

[23] Clark LE, Menderes G, Tower AM, Silasi DA, Azodi M. A simple approach to specimen retrieval via posterior colpotomy incision. JSLS 201519(April-June (2)), doi:http://dx.doi.org/10.4293/JSLS.2014.00222. 